Article

\title{
Impact of Hot-Water Extraction on Acetone-Water Oxygen Delignification of Paulownia Spp. and Lignin Recovery
}

\section{Chen Gong and Biljana M. Bujanovic*}

Department of Paper and Bioprocess Engineering, College of Environmental Science and Forestry, State University of New York, Syracuse, NY 13210, USA; E-Mail: chgong@syr.edu

* Author to whom correspondence should be addressed; E-Mail: bbujanovic@esf.edu; Tel.: +1-315-470-6907.

Received: 9 December 2013; in revised form: 7 February 2014 / Accepted: 17 February 2014 / Published: 19 February 2014

\begin{abstract}
A hardwood-based biorefinery process starting with hot-water extraction (HWE) is recommended in order to remove most of the hemicelluloses/xylans before further processing. HWE may be followed by delignification in acetone/water in the presence of oxygen (AWO) for the production of cellulose and lignin. In this study, the HWE-AWO sequence was evaluated for its effectiveness at removing lignin from the fast-growing species Paulownia tomentosa (PT) and Paulownia elongata (PE), in comparison with the reference species, sugar maple (Acer saccharum, SM). HWE might lead to a remarkable increase in lignin accessibility, and as a result, a greater AWO delignification degree was observed for extracted PT, PE, and SM than for unextracted ones. Organosolv lignin was recovered from the spent liquor of AWO delignification of PT with/without prior HWE and characterized to evaluate the benefits of HWE on the lignin structure and purity. The lignin recovered from the spent liquor of HWE-AWO sequence is of higher purity and lighter color than that recovered from the AWO spent liquor. These properties along with low sulfur content are desirable for lignin high-value applications.
\end{abstract}

Keywords: hot-water extraction; acetone-water oxygen delignification; Paulownia tomentosa; Paulownia elongata; Acer saccharum; organosolv lignin 


\section{Introduction}

Biorefining has been developed based on the concept of converting lignocellulosic biomass to fuels, solvents, chemicals, plastics, and materials to replace traditional refineries based on fossil fuel sources [1]. In a wood-based biorefinery, an appropriate pretreatment to start the conversion of biomass plays a critical role in facilitating further processing to produce three relatively clean streams: cellulose, hemicelluloses, and lignin. The cellulose stream can be used for the production of paper, cellulose derivatives or nanocellulose; if hydrolysis of cellulose is performed, the resulting glucose may be fermented to produce an array of products, including ethanol. Hemicelluloses can also be fermented after hydrolysis or used in their polymer form [1,2]. Lignin is the third main wood constituent, which is considered to be a major cause of the well-documented wood recalcitrance [3]. Even though lignin is the most abundant aromatic polymer on Earth, in the past, lignin has been used mainly for the production of power and energy. It is expected that lignin will take a more prominent role in the production of renewable chemicals and materials, since, unlike any other natural polymer, lignin is uniquely capable of producing many phenolic products [4,5]. Therefore, the production of the three clean streams of major wood constituents, desirably retaining their original structures, is essential for further converting of wood to value-added chemicals or materials.

Hot-water extraction (HWE) is being developed at the State University of New York College of Environmental Science and Forestry (SUNY-ESF). HWE is applied preferentially to hardwoods to generate multiple high-value products. It is performed without chemical input, and hence, without need for chemical regeneration line and disposal costs [1]. Under high temperature $\left(160-170{ }^{\circ} \mathrm{C}\right)$ conditions in water, a chain of autocatalytic reactions occur due to an increase in acidity provided by hydrolysis of acetyl groups in hemicelluloses and later by the production of other acidic compounds (final $\mathrm{pH} \sim 3.5$ ) [6]. In these conditions, hemicelluloses are dissolved due to their relatively low degree of polymerization and branched structure [1]. A recommended standard procedure for HWE lasts for $2 \mathrm{~h}$ at $160{ }^{\circ} \mathrm{C}$ with liquor-to-wood ratio of $4: 1$ [7]. In the previous studies of standard HWE using sugar maple (Acer saccharum) as a model species, a relatively selective removal of hemicelluloses has been confirmed ( $\sim 80 \%$ of total hemicelluloses removed) with a concurrent small removal of lignin $(<10 \%$ of the total lignin). Cleavage of some acid-labile lignin-carbohydrate bonds also has been proposed to occur $[8,9]$.

A simplified biorefinery scheme based on HWE is shown in Scheme 1. The two separate streams produced in HWE, a hot-water extract and hot-water extracted wood, are proposed to produce a rich palette of products. In the utilization of the hot-water extract, research efforts have focused on hydrolysis of extract-containing hemicelluloses and subsequent fermentation of resulting monosaccharides for the production of biofuels and bioplastics [1]. For instance, saccharolytic strains, such as Clostridium acetobutylicum and Clostridium beijerinckii, have been used for fermentation of a variety of sugars to produce neutral solvents consisting of acetone, butanol, and ethanol [10,11]. Some bioplastics may also be obtained, such as polyesters/polyhydroxyalkanoates (PHA) and polylactic acid (PLA) from lactic acid. In addition, the value-added co-products from hot-water extracts, including acetic acid, methanol, formic acid, furfural, and hydroxymethylfurfural, may be recovered by membrane separation of hot-water extracts [1]. For the utilization of hot-water extracted wood, some suggested applications are in the production of combined heat and power (CHP), pellets, reconstituted 
wood products, and pulp/paper [7]. In pulp production, an increase in delignification rate has been observed during kraft pulping [12,13]. This is an important advantage of HWE, which leads to shorter reaction times and the use of fewer chemicals. Even though HWE promotes the rate of delignification in kraft pulping, other alternative delignification processes after hot-water extraction of wood are societally and economically more desirable.

Scheme 1. Biorefinery based on HWE.

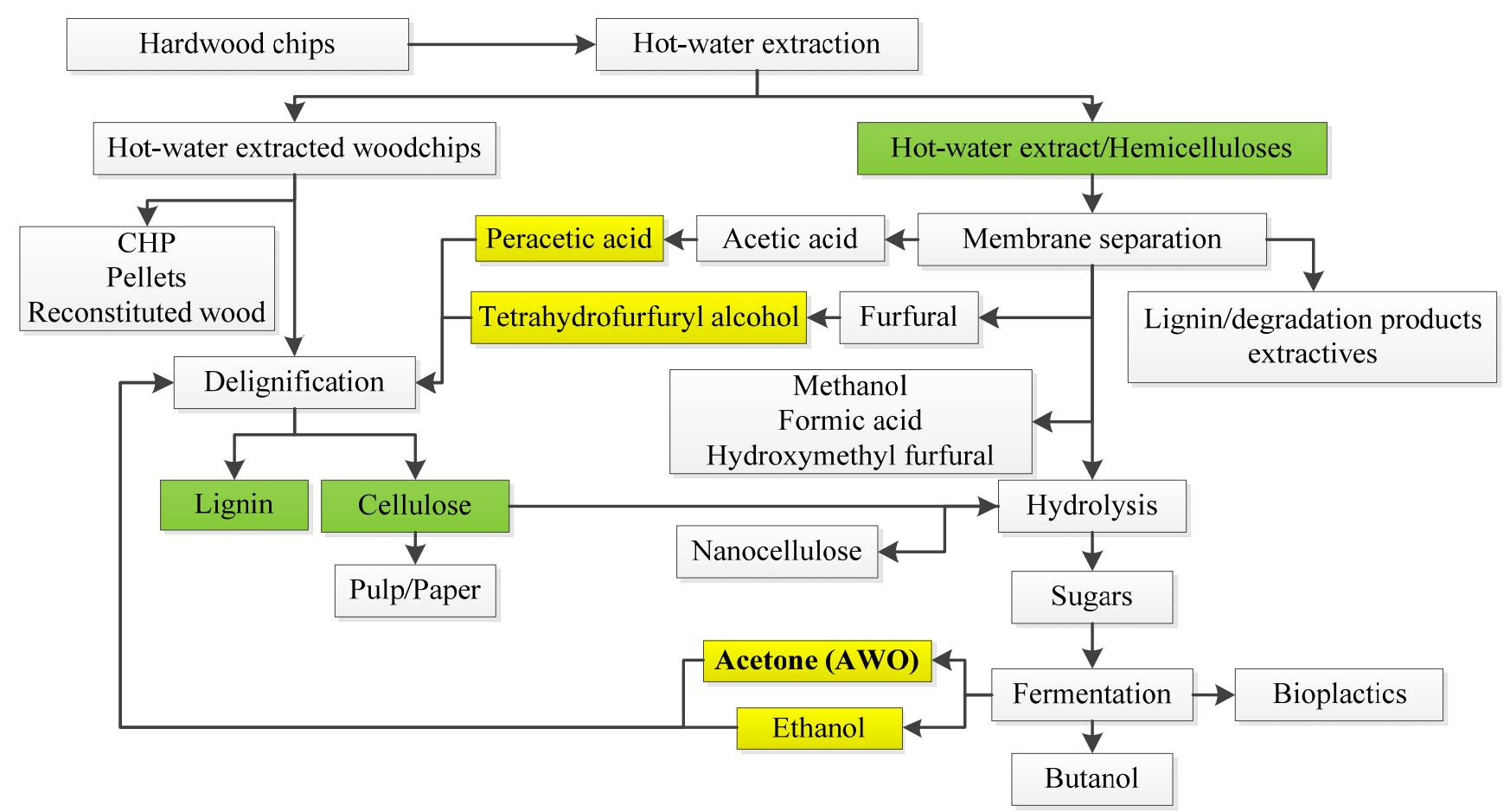

Organosolv pulping was developed as one of the sulfur-free, environmentally more acceptable delignification processes to replace kraft pulping. Important advantages of organosolv compared to kraft pulping include elimination of the emission of reduced forms of sulfur and the accompanying odor, decrease in water usage, and an improved lignin removal efficiency [14-16]. Organosolv processes based on the designed biorefinery products, including tetrahydrofurfuryl alcohol, peracetic acid, ethanol, and acetone (Scheme 1), have been evaluated in our previous study. It has been found that delignification in acetone/water in the presence of oxygen (AWO) is the most efficient delignification method for hot-water extracted sugar maple; a delignification degree of up to $96 \%$ is accomplished with less than $2 \%$ residual lignin [8]. The resulting cellulose may be used for pulp/paper production or for hydrolysis to fermentable glucose and nanocellulose, the choice being primarily dependent upon the strength of cellulose (Scheme 1). The lignin recovered from AWO spent liquor (Scheme 1) is sulfur-free. In addition, lignin produced from hot-water extracted sugar maple contains less residual carbohydrates than lignin produced under the same conditions from unextracted sugar maple [17]. This indicates a potential for use of the AWO lignin produced from hot-water extracted wood as a sustainable alternative for the production of products traditionally produced from fossil sources, such as phenolic and epoxy resins, isocyanates, thermoplastics, and carbon fibers [17-19].

Promising results obtained in fractionation of sugar maple following the HWE-AWO sequence, encouraged us to explore other hardwood species. This report discusses the results obtained for 
Paulownia spp., which have gained increasing attention for use due to their short-rotation and high yields. Well known for its rapid growth, the Paulownia genus, native to China and Japan, first arrived in the United States in the 1840s [20,21]. Within 5 to 7 years after planting, each Paulownia tree can produce $1 \mathrm{~m}^{3}$ of wood, and annual production may yield 150 to $330 \mathrm{t} / \mathrm{ha}$ under intensive plantation, with about 2000 trees per ha. Within 15 years after planting, Paulownia can be harvested for a broad range of applications, including high-value added products [22]. It has been reported that the expected average yield from 40-year-old Paulownia plantations is 250 to $275 \mathrm{~m}^{3} /$ ha in the United States. Given the density of 0.277 to $0.350 \mathrm{~g} / \mathrm{cm}^{3}$ [23], the annual yield of Paulownia (69-96 t/ha) significantly surpasses that of Salix spp. (40-41 t/ha) [24], which is another fast-growing species with great potential as a bioenergy crop. The high production yield also favors the recovery and control of soil, which stabilizes the soil erosion and effectively absorbs carbon dioxide [25]. The suggested use of Paulownia wood is for house construction, furniture making, farm implements, handcraft, veneer, plywood, and paper pulp [26]. Since it was introduced in the United States, Paulownia tomentosa has been naturalized [27], whereas other Paulownia species, such as Paulownia elongata, showed potentially high yields in managed plantations [28]. In regard to this study, the main objective was to assess the use of the previously recommended HWE-AWO sequence for fractionation of two Paulownia spp., Paulownia tomentosa (PT) and Paulownia elongata (PE), in bench-scale experiments and to assess the ability to scale up. Lignin was recovered and characterized from spent liquors to elucidate the impact of HWE on AWO delignification and to assess the potential for application.

\section{Results and Discussion}

\subsection{The Chemical Characterization of Unextracted Wood}

The chemical characterization of Paulownia tomentosa (PT) and Paulownia elongata (PE) is shown in Table 1, including the contents of extractives and lignin (based on oven-dry wood, OD), along with the ratio of main lignin units, syringyl-to-guaiacyl ratio ( $\mathrm{S} / \mathrm{G}$ ratio). The results of chemical characterization of sugar maple (SM), as a reference species, are also included. The acetone/water (9:1, v/v; AW) extractives of the Paulownia species (PT: 8.8\%; PE: 5.6\%) are greater than previously reported values for Paulownia (PT: 6\% methanol extractives; PE: 2.3\% ethanol extractives, 3.76\% alcohol/benzene extractives, $2.7 \%$ acetone extractives) [29-32], which demonstrates that the chemical nature of selected solvent has a significant effect on the amount of extractives dissolved. With the highest amount of dissolved extractives, AW appears to be a powerful solvent, especially for phenolic extractives (e.g., extraction with AW prior to isolation of lignin [33]). The AW extractive content of Paulownia is also higher than that of the reference species, SM, which may be attributed to some extent to the presence of the AW soluble phenylpropanoid glycosides in Paulownia species [34].

The Klason lignin content of PT $(21.2 \%)$ is in the range of reported Klason values for PT (20.3\%-22.1\%) [30,35-37]. The Klason lignin content measured for PE (23.8\%) is greater than the previously reported data $(20.5 \%-20.75 \%)$ [29,32], but is close to that stated by Akyildiz (2013) $(21 \%-23 \%)$ [38]. Among these three samples, the lignin content is inversely related to the $\mathrm{S} / \mathrm{G}$ ratio (lignin: $\mathrm{PE}>\mathrm{PT}>\mathrm{SM}$; $\mathrm{S} / \mathrm{G}$ : $\mathrm{PE}<\mathrm{PT}<\mathrm{SM}$ ), i.e., a decrease in the lignin content is associated with an increase of $\mathrm{S} / \mathrm{G}$ ratio as observed earlier [39]. 
Table 1. The contents of extractives and lignin, and S/G ratio in PT, PE, and SM.

\begin{tabular}{ccccccc}
\hline \multirow{2}{*}{ Sample } & $\begin{array}{c}\text { Extractives } \\
\text { \% OD wood }\end{array}$ & & \multicolumn{3}{c}{$\begin{array}{c}\text { Lignin } \\
\text { \% OD wood }\end{array}$} & \multirow{2}{*}{ S/G ratio } \\
\cline { 2 - 3 } & $\mathbf{A W}$ & & Klason & $\mathbf{A S} *$ & Total & \\
\hline PT & 8.8 & & 21.2 & 2.6 & 23.8 & 0.98 \\
$\mathrm{PE}$ & 5.6 & & 23.8 & 2.2 & 26.0 & 0.88 \\
$\mathrm{SM} * *$ & 3.2 & & 18.1 & 3.9 & 22.0 & 1.92 \\
\hline \multicolumn{3}{c}{$*$ AS stands for acid-soluble lignin; ** cited from $[8,40]}$.
\end{tabular}

\subsection{HWE: Parr Reactor and $M / K$ Digester}

Table 2 shows the comparative results of hot-water extraction (HWE) performed in a Parr reactor and an $\mathrm{M} / \mathrm{K}$ digester (a detailed experimental scheme shown in the Experimental Section, Scheme 2). In regard to the results of HWE performed on Paulownia species in a Parr reactor, a higher amount of PT is dissolved in comparison to PE (Table 2). This may be attributed to: (a) a greater xylan content in PT compared to PE (cf. 23.8\%-24.8\% vs. 13.8\%) [29,35,36]; (b) a greater amount of lignin of PT dissolved compared to PE (expressed as the delignification degree, DD in Table 2). The solubility of PT is also higher than that of SM (mass loss: PT 37.5\% vs. SM 31.4\% in Table 2). These results also demonstrate that PT should be considered as a valuable raw material for biorefinery based on HWE, and scale-up might be recommended. In our previous study, two levels of scale-up have been accomplished for HWE ( $2 \mathrm{~L} \mathrm{M} / \mathrm{K}$ digester and $65 \mathrm{ft}^{3}$ digester). Under the same operation, including temperature, time, and liquor-to-wood ratio (L/W) of 4:1, the hot-water extracted wood from these two digesters had comparable yield [1,7]. Therefore, HWE of PT chips were scaled up from a Parr reactor to an $\mathrm{M} / \mathrm{K}$ digester, and the results were compared with those obtained for SM under the similar conditions.

Table 2. The HWE comparison between Parr reactor and $\mathrm{M} / \mathrm{K}$ digester.

\begin{tabular}{|c|c|c|c|c|c|c|c|c|}
\hline \multicolumn{4}{|c|}{ Conditions: Time: $2 \mathrm{~h}$, temperature: $160^{\circ} \mathrm{C}$} & \multirow{2}{*}{$\begin{array}{c}\text { Yield } \\
\% \text { OD wood }\end{array}$} & \multicolumn{3}{|c|}{$\begin{array}{c}\text { Lignin } \\
\% \text { extracted wood }\end{array}$} & \multirow{2}{*}{$\begin{array}{c}\text { DD * } \\
\%\end{array}$} \\
\hline Reactors & Sample & $\mathbf{L} / \mathbf{W}$ & Particle size & & Klason & AS & Total & \\
\hline \multirow{3}{*}{$\begin{array}{l}\text { Parr } \\
\text { reactor }\end{array}$} & PT & 50 & $0.595 \mathrm{~mm}$ & 62.5 & 26.8 & 1.3 & 28.1 & 26.1 \\
\hline & $\mathrm{PE}$ & 50 & $0.595 \mathrm{~mm}$ & 68.8 & 28.3 & 1.6 & 29.9 & 20.9 \\
\hline & SM & 50 & $0.595 \mathrm{~mm}$ & 68.6 & 20.3 & 2.0 & 22.3 & 30.4 \\
\hline \multirow{2}{*}{$\begin{array}{c}\mathrm{M} / \mathrm{K} \\
\text { digester }\end{array}$} & PT & 8 & $1 / 4 "$ accepts & 69.9 & 27.1 & 1.6 & 28.7 & 15.7 \\
\hline & SM & 4 & 3/8", 5/8", 7/8" accepts & 77.0 & 23.9 & 2.0 & 25.9 & 9.4 \\
\hline
\end{tabular}

* DD — delignification degree refers to the amount of lignin removed, expressed in percentages of the amount of lignin present in wood before delignification.

Due to the larger particle size and lower L/W, the solubility of PT and SM are lower in an M/K than in a Parr reactor (Table 2). Dissolution of PT and SM decreases by about $25 \%$ and $36 \%$, respectively (change in the solubilization level based on the original OD mass: PT: Parr 37.5\% vs. M/K 30.1\% ( $\Delta 25 \%)$; SM: Parr 31.4\% vs. M/K 23.0\% ( $\Delta 36 \%)$ ). This decreased dissolution reveals that a gradual decrease in solubility is associated with an increase in particle size and a decrease in L/W ratio. It should be noted that due to practical considerations in using the $\mathrm{M} / \mathrm{K}$ digester, the increase in particle size upon scale-up was less for PT than for SM, also the L/W ratio was decreased by a lesser 
margin for PT than for SM. For these reasons, the solubility of PT is less affected by scale-up than the solubility of SM (Table 2).

Along with the removal of most of the hemicelluloses, wood undergoes a series of autocatalytic reactions during HWE leading to the removal of certain low amount of lignin [1,6-9]. For the HWE performed in a Parr reactor, a decreasing order of DD may be ranked in the following: SM $>$ PT $>$ PE. This is also in accordance with a decreasing order of the $\mathrm{S} / \mathrm{G}$ ratio observed for these species $(\mathrm{S} / \mathrm{G}$ : $\mathrm{SM}>\mathrm{PT}>\mathrm{PE}$ ). The DD is remarkably affected by scale-up, decreasing more than three times for SM and less than two times for PT, which is again in accordance with the aforementioned difference in particle size and $\mathrm{L} / \mathrm{W}$ ratio used in $\mathrm{M} / \mathrm{K}$ experiments for these two species (Table 2).

\subsection{The Results of AWO Delignification with/without HWE}

The delignification results achieved in the AWO process using unextracted and hot-water extracted wood are shown in Table 3. AWO delignification performed on unextracted wood shows the best results for PT. While PT and PE are characterized by similar density (PT: $340 \mathrm{~kg} / \mathrm{m}^{3}$; PE: $335 \mathrm{~kg} / \mathrm{m}^{3}$ [23]) of wood, PT shows a greater DD in accordance with the greater S/G ratio. SM, however, is characterized by over two times greater density $\left(705 \mathrm{~kg} / \mathrm{m}^{3}\right.$ [41]) than Paulownia species. The consequent negative effect of low porosity of wood on delignification appears to exceed a positive effect of the relatively high $\mathrm{S} / \mathrm{G}$ ratio found for SM; DD achieved in AWO of SM is less than DD of both Paulownia species by at least 1.3 times.

The results of HWE-AWO sequence clearly indicate that HWE promotes the AWO delignification for all three species, since a higher DD and a better delignification selectivity (DS) are accomplished in AWO of hot-water extracted wood. This beneficial effect of HWE may be attributed to the resulting changes in the physicochemical structure of wood, including an increase in porosity, a higher content of phenolic hydroxyl groups, a lower molecular weight of residual lignin, and, most likely, a weaker association between lignin and carbohydrates in extracted wood [1,8,9,42-45]. Between the two Paulownia species, both exhibit same remarkable DS in AWO after HWE; the DD of E Parr $_{\text {PT is greater }}$ than that of $\mathrm{E}_{\mathrm{Parr}} \mathrm{PE}$, indicating a more disrupted physicochemical structure of hot-water extracted PT wood (in accordance with its greater solubility and DD in Table 2). Based on the AWO delignification results obtained for PT and SM species, it can be concluded that HWE-AWO sequence results in a superior delignification for both species, with comparable DD and DS. It should be noted that a moderate increase in DD is observed for $\mathrm{E}_{\mathrm{MK}} \mathrm{PT}$ in comparison to PT (95.7\% vs. 93.6\%, respectively), indicating only a slight increase in lignin accessibility during HWE. As for SM, HWE may contribute to a remarkable change in accessibility of lignin, as a result, more than a 1.8 -fold increase in DD of $\mathrm{E}_{\mathrm{MK}} \mathrm{SM}$ is observed in comparison to SM. This result validates use of the HWE-AWO sequence for sugar maple in regard to the delignification success. In the case of both PT and SM, HWE-AWO sequence may be recommended to produce separate streams of main wood constituents: a hemicellulose stream in HWE and a lignin stream in the AWO delignification, along with the cellulose product. 
Table 3. Comparative results of AWO delignification.

\begin{tabular}{|c|c|c|c|c|c|c|}
\hline \multirow[t]{2}{*}{ Sample } & \multirow{2}{*}{$\begin{array}{c}\text { Yield } \\
\% \text { OD wood }\end{array}$} & \multicolumn{3}{|c|}{$\begin{array}{c}\text { Residual lignin } \\
\% \text { delignified wood }\end{array}$} & \multirow[t]{2}{*}{ DD *\% } & \multirow[t]{2}{*}{ DS ** } \\
\hline & & Klason & $\mathbf{A S}$ & Total & & \\
\hline $\mathrm{PE}$ & 67.1 & 9.6 & 1.8 & 11.4 & 70.7 & 0.28 \\
\hline $\mathrm{E}_{\text {Parr }} \mathrm{PE}$ & 71.9 & 5.2 & 0.7 & 5.9 & 85.8 & 0.04 \\
\hline PT & 50.0 & 1.7 & 1.3 & 3.0 & 93.6 & 0.39 \\
\hline $\mathrm{E}_{\text {Parr }} \mathrm{PT}$ & 69.3 & 1.2 & 0.8 & 2.0 & 95.1 & 0.06 \\
\hline $\mathrm{E}_{\mathrm{MK}} \mathrm{PT}$ & 62.5 & 1.2 & 0.8 & 2.0 & 95.7 & 0.15 \\
\hline $\mathrm{SM}$ & 73.7 & 10.8 & 3.1 & 13.9 & 53.4 & 0.35 \\
\hline $\mathrm{E}_{\mathrm{MK}} \mathrm{SM}$ & 59.7 & 0.8 & 0.8 & 1.6 & 96.3 & 0.22 \\
\hline
\end{tabular}

Conditions: A/W 6:4, v/v; time $2 \mathrm{~h}$; temp. $150{ }^{\circ} \mathrm{C}$; oxygen $200 \mathrm{psi}$ * DD-delignification degree refers to the amount of lignin removed, expressed in percentages of the amount of lignin present in wood before delignification; ** DS - delignification selectivity expressed as the ratio of the $\%$ of the total carbohydrates removed and the $\%$ of the total lignin removed; lower number indicates better selectivity.

\subsection{Lignin Isolation from the Spent Liquor of AWO Delignification of PT and $E_{M K} P T$}

To clarify further the effect of HWE on AWO delignification, lignin was isolated from the spent liquor of $\mathrm{AWO}$ delignification of $\mathrm{PT}$ and $\mathrm{E}_{\mathrm{MK}} \mathrm{PT}$ and assessed its utility (lignin isolation scheme presented in the Experimental Section, Scheme 2). As shown in Table 4, the isolated precipitates containing high-molecular weight lignin $\left(\mathrm{PTL}_{1}\right.$ and $\left.\mathrm{E}_{\mathrm{MK}} \mathrm{PTL}_{1}\right)$ are comparable in the yield based on the mass of original wood. A higher amount of the low-molecular weight lignin degradation products is recovered from the AWO spent liquor of $\mathrm{E}_{\mathrm{MK}} \mathrm{PT}$ in comparison to that of $\mathrm{PT}\left(\mathrm{E}_{\mathrm{MK}} \mathrm{PTL}_{2}>\mathrm{PTL}_{2}\right.$; $\mathrm{E}_{\mathrm{MK}} \mathrm{PTL}_{3}>\mathrm{PTL}_{3}$ ). Therefore, a higher total yield of lignin/lignin degradation compounds is recovered from the spent liquor of $\mathrm{E}_{\mathrm{MK}} \mathrm{PT}$. As based on the dissolved wood, a higher total yield of lignin is recovered from $\mathrm{E}_{\mathrm{MK}} \mathrm{PT}$ than from $\mathrm{PT}$ (58.4\% vs. 35.5\%). This result indicates that AWO performed after HWE removes lignin more efficiently than other wood constituents, which is in accordance with previously noted better delignification selectivity of HWE-AWO sequence (Table 3). As based on the lignin removed from wood, a lower amount of high-molecular weight lignin is recovered from spent liquor of $\mathrm{E}_{\mathrm{MK}} \mathrm{PT}$ than from that of $\mathrm{PT}\left(\mathrm{E}_{\mathrm{MK}} \mathrm{PTL}_{1}<\mathrm{PTL}_{1}\right)$. This result, combined with a higher total recovery yield of lignin degradation compounds observed for $\mathrm{E}_{\mathrm{MK}} \mathrm{PT}$ than for PT $\left(\mathrm{E}_{\mathrm{MK}} \mathrm{PTL}_{2}+\mathrm{E}_{\mathrm{MK}} \mathrm{PTL}_{3}>\mathrm{PTL}_{2}+\mathrm{PTL}_{3}\right)$, indicates more severe lignin changes taking place during AWO of $\mathrm{E}_{\mathrm{MK}} \mathrm{PT}$. However, the recovery procedure used in these experiments fails to recover the whole amount of lignin removed in AWO delignification of PT/ $\mathrm{E}_{\mathrm{MK}} \mathrm{PT}$. This might be attributed to the lignin conversion to compounds, which are not extractable by selected organic solvents (e.g., the formation of hydrophilic compounds, such as carboxyl acids resulting from the cleavage of aromatic ring [46]). A higher lignin content of $\mathrm{E}_{\mathrm{MK}} \mathrm{PTL}_{1}$ than of $\mathrm{PTL}_{1}$ determined in these experiments (88.0\% vs. 81.8\%) demonstrates the beneficial effect of HWE on the purity of lignin recovered: the cleavage of lignin-carbohydrate bonds occurs to some extent during HWE [8,40,43]. Both isolated lignins (produced in sulfur-free processes) are light in color compared to sulfur-containing kraft lignin (Figure 1). This may be a desirable feature of the AWO lignin when it is considered for high-value applications. 
Table 4. Lignin and lignin degradation products recovered from the spent liquor of AWO delignification of PT and $\mathrm{E}_{\mathrm{MK}} \mathrm{PT}$.

\begin{tabular}{ccc}
\hline Fraction of recovered lignin & Yield \% original wood & Yield \% lignin removed \\
\hline $\mathrm{PTL}_{1}$ & 10.5 & 47.0 \\
$\mathrm{PTL}_{2}$ & 5.1 & 24.2 \\
$\mathrm{PTL}_{3}$ & 1.5 & 7.1 \\
Total yield & $17.1(35.5) *$ & - \\
$\mathrm{E}_{\mathrm{MK}} \mathrm{PTL}_{1}$ & 11.2 & 40.6 \\
$\mathrm{E}_{\mathrm{MK}} \mathrm{PTL}_{2}$ & 8.1 & 30.7 \\
$\mathrm{E}_{\mathrm{MK}} \mathrm{PTL}_{3}$ & 2.6 & 9.7 \\
Total yield & $21.9(58.4) *$ & - \\
\hline
\end{tabular}

* Based on the loss of wood during AWO.

Figure 1. The picture shows kraft lignin compared to AWO lignin (a) Kraft lignin; (b) $\mathrm{PTL}_{1} ;$ (c) $\mathrm{E}_{\mathrm{MK}} \mathrm{PTL}_{1}$.

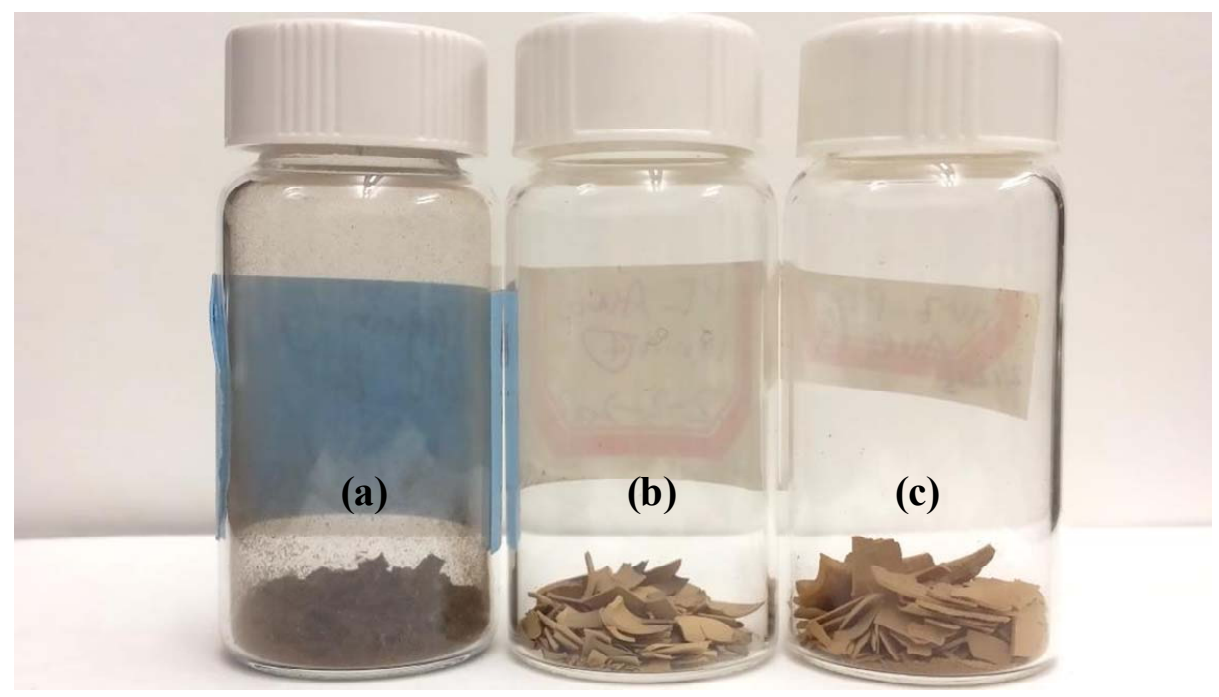

\subsection{Lignin Characterization by 2D HSQC NMR}

2D-NMR is a powerful tool for characterization of lignin structures and carbohydrate correlations. The domain lignin structures and some of the carbohydrate correlations are assigned by comparison with previous data [47-50]. In the spectrum of $\mathrm{PTL}_{1}$ (Figure 2), the $\beta-\mathrm{O}-4$ correlations $\left(\mathrm{A}_{\alpha}, \mathrm{A}_{\beta}, \mathrm{A}_{\gamma}\right.$ present) dominate the lignin side-chain region, however, there is no enough evidence to confirm the presence of the phenylcoumaran $\left(\beta-5 ; B_{\beta}\right.$ present) and resinol $\left(\beta-\beta ; C_{\alpha}\right.$ present) structures, which commonly appear in lignin along with the dominant $\beta-\mathrm{O}-4$ structure. In addition, abundantly present carbohydrate correlations represent xylose- and glucose- based polysaccharides $[48,49]$. In regard to the spectrum of $\mathrm{E}_{\mathrm{MK}} \mathrm{PTL}_{1}$, typical lignin structures $\beta-\mathrm{O}-4, \beta-\beta$, and $\beta-5$ can be readily assigned. Carbohydrate correlations are not noticeable indicating high purity of $\mathrm{E}_{\mathrm{MK}_{\mathrm{PTL}}} \mathrm{PL}_{1}$. It can be concluded that the NMR results support the results of the lignin content determination, which also showed that $\mathrm{E}_{\mathrm{MK}} \mathrm{PTL}_{1}$ contain more lignin than $\mathrm{PTL}_{1}(88.0 \%$ vs. $81.8 \%)$. Moreover, it is evident that there is a discrepancy between the purity found for $\mathrm{E}_{\mathrm{MK}} \mathrm{PTL}_{1}$ by the total lignin content determination (sum of acid-insoluble and acid-soluble lignin) and the absence of carbohydrate correlations in respective 
HSQC spectrum. This discrepancy might be attributed to an imperfect way of the UV determination of acid-soluble lignin, which includes using an average absorptivity value of $110 \mathrm{~L} \cdot \mathrm{g}^{-1} \cdot \mathrm{cm}^{-1}$. Dependent on the source and previous history of the wood or pulp sample, however, this absorptivity value may vary to a greater or lesser degree [42]. The lignin isolated in these experiments has undergone an oxidative acidic treatment, leading to substantial changes of lignin structure. A decrease in the lignin absorption in UV area is expected as a result of these changes and might offer evidence for decrease in lignin aromaticity/aromatic cleavage during AWO [46,51]. Additionally, the main cross-signals from syringyl (S) and guaiacyl (G) lignin units can be observed in both $\mathrm{PTL}_{1}$ and $\mathrm{E}_{\mathrm{MK}} \mathrm{PTL}_{1}$ in the aromatic region of the HSQC spectra. The S-lignin units show a prominent signal for the $\mathrm{C}_{2,6}-\mathrm{H}_{2,6}$ correlation, while the $\mathrm{G}$ units show different correlations for $\mathrm{C}_{2}-\mathrm{H}_{2}, \mathrm{C}_{5}-\mathrm{H}_{5}, \mathrm{C}_{6}-\mathrm{H}_{6}$. Signals corresponding to $\mathrm{C}_{2,6}-\mathrm{H}_{2,6}$ correlations in $\mathrm{C}_{\alpha}$-oxidized S-lignin units $\left(\mathrm{S}^{\prime}\right)$ are also observed in both spectra, which may suggest that lignin oxidation occurs during AWO [47].

Figure 2. HSQC spectrum of acetylated organosolv lignin in $\mathrm{CDCl}_{3}$ : (a) $\mathrm{PTL}_{1}$; (b) $\mathrm{E}_{\mathrm{MK}} \mathrm{PTL}_{1}$. Correlations from main lignin structures, and some of the characteristic polysaccharide correlations are shown in color. Color coding correlates to the structures shown. Xyl stands for xylose-based polysaccharides; Glu stands for glucose-based polysaccharides.

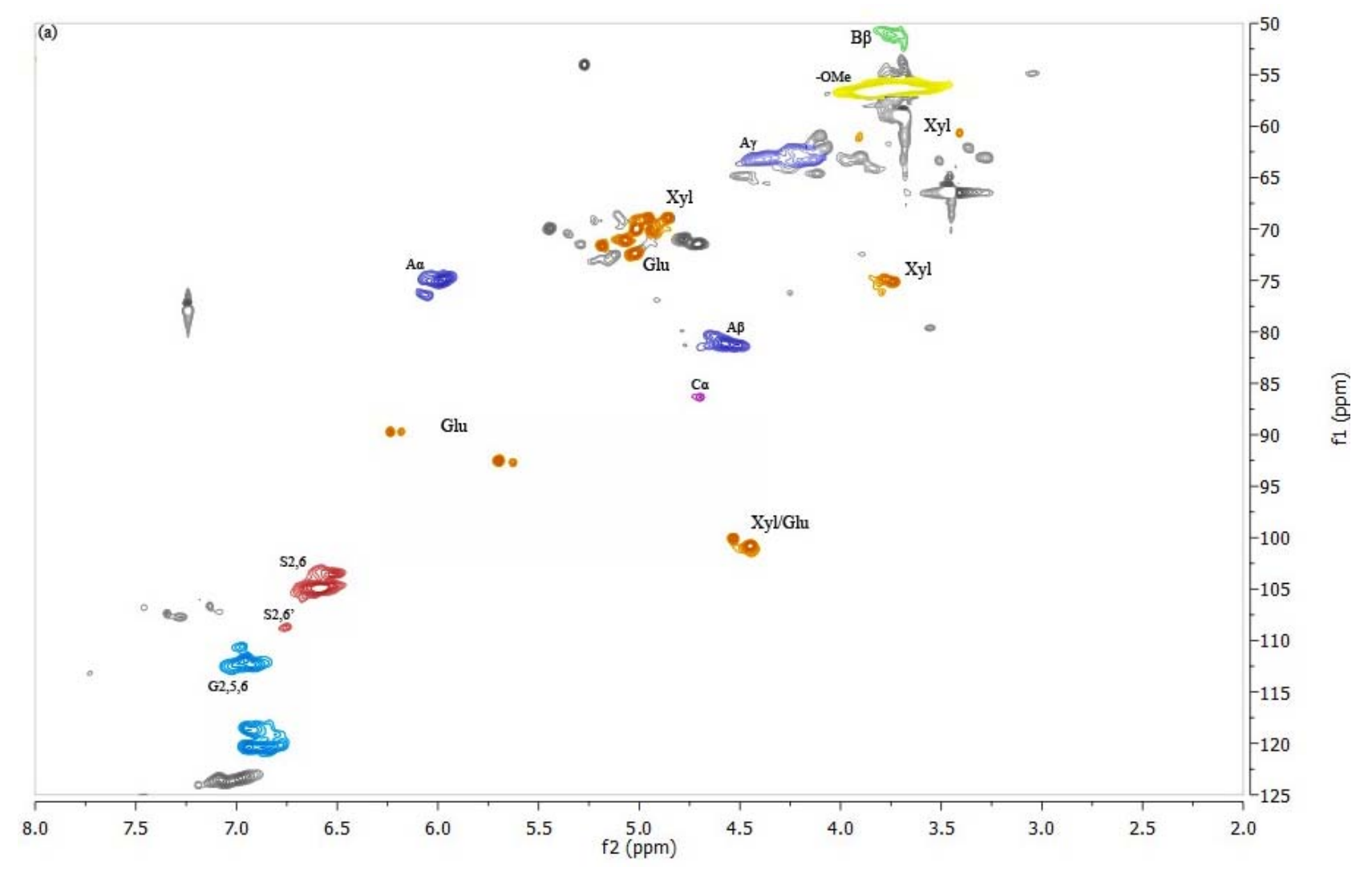


Figure 2. Cont.

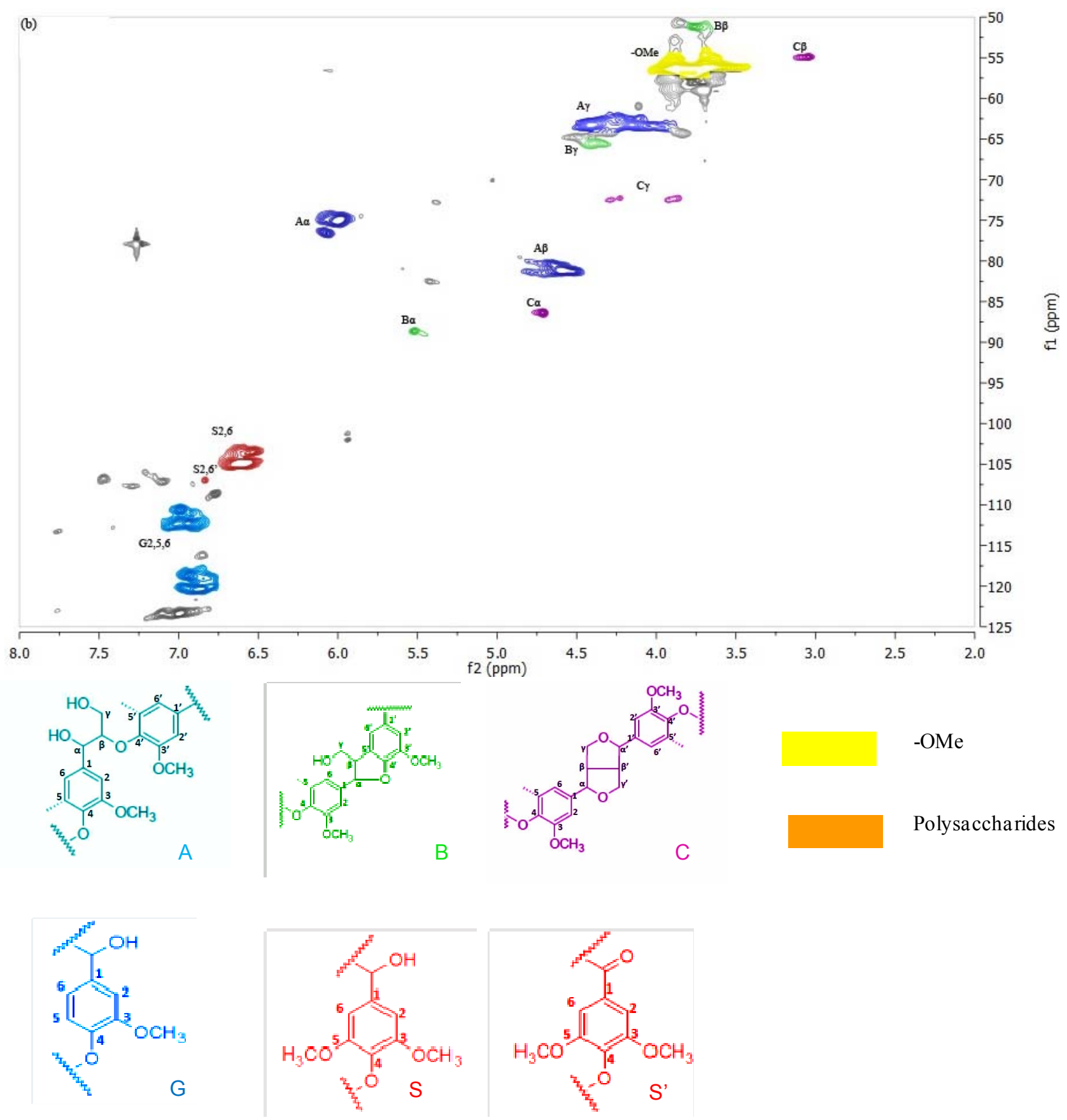

\section{Experimental Section}

\subsection{Materials}

Paulownia tomentosa (PT) and Paulownia elongata (PE) were supplied by American Paulownia Association, Inc. (Hagerstown, MD, USA). Harvests of Paulownia Spp. were from plantations in the 14-18 year old range. Sugar maple (Acer saccharum) (SM) wood was supplied from the SUNY-ESF Lafayette Road Experimental Station in Syracuse, NY, USA. The Paulownia woods were chipped on a Carthage chipper and screened by using a Williams Classifier with $1 / 4$ " accepts, while SM was chipped with 3/8", 5/8", and 7/8" accepts. PT, PE, and SM were milled using a Wiley Mill to 30 mesh 
for the hot-water extraction (HWE) and organosolv delignification studies (Parr reactor experiments) to eliminate the diffusion problems and to fulfill the device requirements (Subsection 3.2.1. Experiments with woodmeal). Between these two Paulownia species, the one with better delignification results was selected to perform a larger-scale HWE pretreatment with wood size of 1/4" accepts (Subsection 3.2.2. Experiments with woodchips). The extracted chips were milled using Wiley Mill to 30 mesh for the organosolv delignification experiments (Subsection 3.2.1. Experiments with woodmeal). After HWE, the end $\mathrm{pH}$ of filtrate was measured (on average 3.5, with a standard deviation of 0.474 ). The experimental scheme is shown in Scheme 2.

Scheme 2. Experimental scheme.

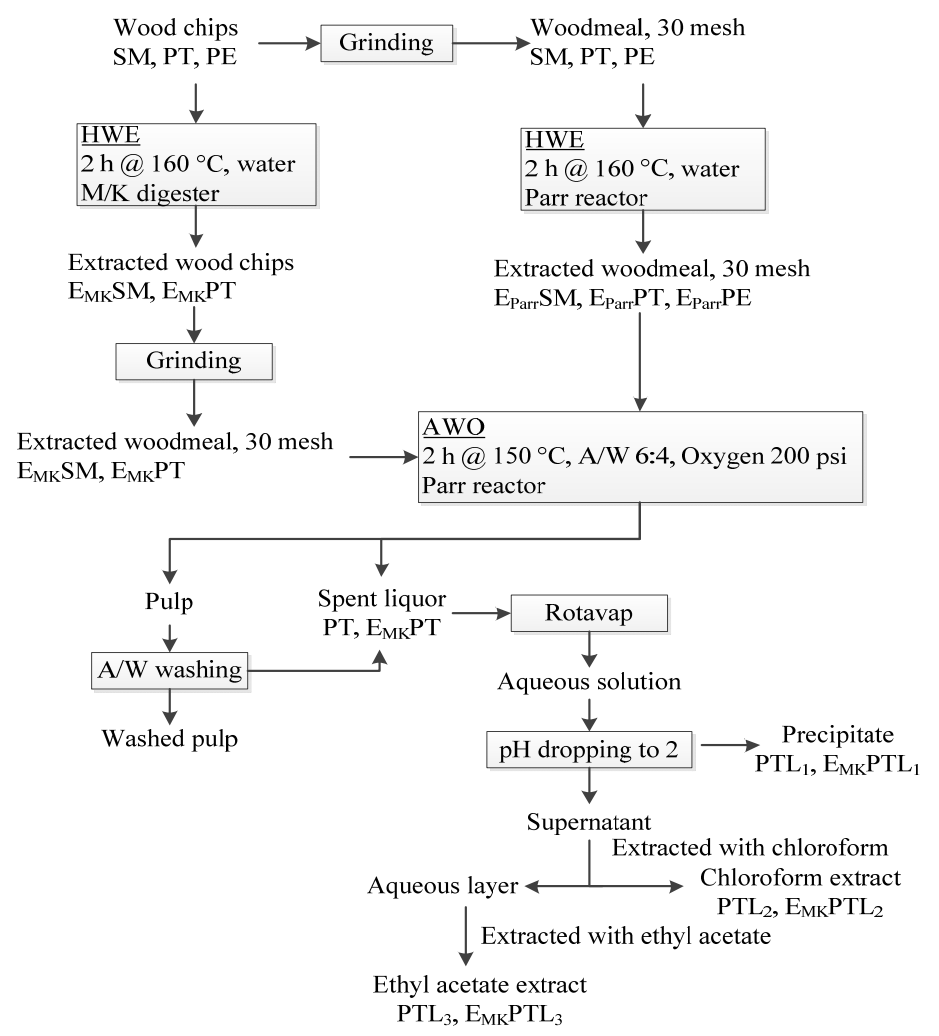

\subsection{Experimental Procedure}

\subsubsection{Experiments with Woodmeal}

HWE: milled wood was extracted using hot water $\left(160^{\circ} \mathrm{C}\right.$; time to temperature $\left.15 \mathrm{~min}\right)$ for two hours at a L/W of 50 to 1 in a $300 \mathrm{~mL}$ Parr reactor (4560 Mini bench top reactor, Parr Instrument Company, Moline, IL, USA) (5 g OD wood; based on oven-dry, or OD wood mass). After HWE, solid wood residue was washed with distilled water until the filtrate was colorless and measured for the yield of extracted wood (based on the original OD wood). The samples of hot-water extracted woodmeal (E $\mathrm{E}_{\text {Parr }} \mathrm{PT}$ and $\mathrm{E}_{\mathrm{Parr}} \mathrm{PE}$ ) were extracted with dichloromethane (DCM; ultra-sonication, $1 \mathrm{~h}$ twice).

Organosolv delignification: experiments were carried out in a $300 \mathrm{~mL}$ Parr reactor (4560 Mini bench top reactor) using acetone/water in the presence of oxygen (AWO). The conditions were as 
follows: time to maximal temperature $\left(\mathrm{T}_{\max }\right) 60 \mathrm{~min} ; \mathrm{T}_{\max } 150{ }^{\circ} \mathrm{C}$; time at $\mathrm{T}_{\max } 120 \mathrm{~min} ; 2 \%$ consistency; oxygen pressure $1.38 \mathrm{MPa}$ (200 psi); acetone/water $(6: 4, v / v)$ [51].

At the end of delignification, the pulp was washed $(3 \times 30 \mathrm{~mL})$ using acetone/water $(6: 4, v / v ; \mathrm{A} / \mathrm{W})$. The resulting yields and residual lignin contents were determined. The filtrate was combined with washing liquor, resulting in spent liquor for further analysis. The delignification degree and delignification selectivity were calculated. In the present study, the delignification degree refers to the amount of lignin removed based on the amount of lignin present in wood before delignification. The delignification selectivity is expressed as the percentage of the total carbohydrates removed divided by the percentage of the total lignin removed.

\subsubsection{Experiments with Woodchips}

HWE: Paulownia woodchips were extracted using hot water $\left(160^{\circ} \mathrm{C}\right.$; time to temperature $\left.45 \mathrm{~min}\right)$ for two hours at a L/W of 8 to 1 in an M/K digester (250 g OD wood). HWE of SM was performed at the same condition except for the L/W (4 to 1; $500 \mathrm{~g}$ OD wood). After HWE, woodchips were washed twice with water at $80{ }^{\circ} \mathrm{C}$ for $15 \mathrm{~min}$, and the yield of hot-water extracted wood chips $\left(\mathrm{E}_{\mathrm{MK}} \mathrm{PT}\right.$ and $\mathrm{E}_{\mathrm{MK}} \mathrm{SM}$ ) was determined. For the delignification experiments unextracted and hot-water extracted woodchips were milled using Wiley Mill to 30 mesh before use. The organosolv delignification was performed in a Parr reactor as previously described.

\subsubsection{Lignin Isolation Procedures}

AWO spent liquor was evaporated under reduced pressure in a rotary evaporator to remove acetone. The $\mathrm{pH}$ of the aqueous liquor was reduced to 2 with $20 \%$ sulfuric acid. The lignin precipitate was collected by centrifugation and vacuum-dried as organosolv lignin $\left(\mathrm{L}_{1}\right)$. The supernatant was collected. The yield of $\mathrm{L}_{1}$ was calculated based on the mass of original woodmeal and based on the amount of lignin removed during delignification. Liquid-liquid extraction of the collected supernatants was performed using chloroform followed by ethyl acetate. Based on these experiments, the yield of low-molecular weight lignin degradation compounds (chloroform extract: $\mathrm{L}_{2}$; ethyl acetate: $\mathrm{L}_{3}$ ) was determined [52].

\subsection{Analytical Methods}

\subsubsection{Chemical Characterization Wood, Hot-Water Extracted Wood, Pulp, and Lignin}

Before lignin analysis in accordance with modified Klason lignin method [42], native wood was extracted with acetone/water $(9: 1, v / v ; \mathrm{AW})$, whereas hot-water extracted wood, pulp, and lignin were extracted with DCM. After hot-water extraction lignin becomes soluble in AW, which is a common solvent used for pre-extraction of native (unextreacted) wood. DCM is used for hot-water extracted wood to retain lignin prior to lignin determination [8]. The Klason and acid-soluble lignin contents were tested using respective extracted samples. 
The $\mathrm{S} / \mathrm{G}$ ratio of wood was determined following a modified nitrobenzene oxidation [39]. The S/G ratio was determined using the following equation:

$$
\mathrm{S} / \mathrm{G} \text { Ratio }=(\mathrm{S} 1+\mathrm{S} 2) \times 1.04 /(\mathrm{G} 1+\mathrm{G} 2) \times 1.50
$$

suggested by Bose and coworkers [39].

\subsubsection{Characterization of Lignin}

The crude lignin was purified with DCM and acetylated before analysis (after $24 \mathrm{~h}$ treatment in acetic anhydride/pyridine, 1:1 v/v, and recovered by rotavap with ethanol to remove the pyridine). The 2D HSQC (heteronuclear single quantum correlation) NMR experiments were acquired at $30^{\circ} \mathrm{C}$ with a Bruker AVANCE III 600 spectrometer $\left(600 \mathrm{MHz}{ }^{1} \mathrm{H}\right.$ frequency, Bruker Biospin Corporation, Billerica, MA, USA) equipped with a $5 \mathrm{~mm}$ triple resonance $z$-gradient probe. Data was processed in Topspin v 3.2 from Bruker Biospin. Acetylated samples were dissolved in $\mathrm{CDCl}_{3}$ and the central chloroform solvent peak was used as internal reference $\left(\delta_{\mathrm{C}} 77.0\right.$ and $\left.\delta_{\mathrm{H}} 7.26 \mathrm{ppm}\right)$. The DEPT edited HSQC experiments had the following parameters: acquired from 11.8 to $-0.2 \mathrm{ppm}$ in $\mathrm{F}_{2}\left({ }^{1} \mathrm{H}\right)$ using 1024 data points (acquisition time of $71 \mathrm{~ms}$ ), 220 to $0 \mathrm{ppm}$ in $\mathrm{F}_{1}\left({ }^{13} \mathrm{C}\right)$ using 400 increments, 80 scans with $1.5 \mathrm{~s}$ interscan delay, total acquisition time of $14 \mathrm{~h}$ for each sample. Processing used typical squared sine-bell apodization in $\mathrm{F}_{2}$ and $\mathrm{F}_{1}$.

\section{Conclusions}

The results reported in the present study were obtained during oxygen pressurized acetone/water delignification (AWO) using Paulownia tomentosa (PT) and Paulownia elongata (PE), with and without hot-water extraction (HWE) performed prior to AWO. Compared to PE, PT resulted in a higher solubility and a higher delignification during HWE. Therefore PT was selected for a larger-scale HWE pretreatment in an $\mathrm{M} / \mathrm{K}$ digester, in comparison with reference species, sugar maple (Acer saccharum) (SM). HWE promoted the AWO delignification efficiency for all species with a higher delignification degree and a better delignification selectivity obtained for extracted wood than for unextracted wood. The remarkable delignification results were observed for hot-water extracted PT and SM, indicating that HWE-AWO sequence may be recommended to produce separate streams of main wood constituents: a hemicellulose stream in HWE and a lignin stream in the AWO delignification, along with the cellulose product. The organosolv lignin was isolated to elucidate the effect of HWE on the purity of lignin and lignin structure. HWE afforded a higher purity of the lignin precipitate with lignin main structures confirmed by 2D HSQC NMR. Compared to kraft lignin, the organosolv lignin isolated from HWE-AWO sequence was shown with much lighter color, suggesting a potential use for high-value applications. Also, the HWE prior to AWO process resulted in a higher amount of lignin degradation products, which were not recoverable by selected organic solvents, indicating the extensive cleavage of the aromatic rings.

\section{Acknowledgments}

We would like to express our appreciation to Thomas E. Amidon for his work on hot-water extraction and continuous support of this work. We sincerely appreciate the generous support of 
American Paulownia Association and SUNY-ESF for the raw materials. We also thank Dave Kiemle for 2D NMR analysis, Mangesh J. Goundalkar, Christopher D. Wood, and Raymond J. Appleby for help with experiments. This work is supported by the USDA-McIntire-Stennis "Enhancing production of uniform high purity lignin" and NSF- PFI-BIC: "Technology Enhancement of Hot Water Extraction" research grants.

\section{Conflicts of Interest}

The authors declare no conflict of interest.

\section{References}

1. Amidon, T.E.; Wood, C.D.; Shupe, A.M.; Wang, Y.; Graves, M.; Liu, S. Biorefinery: Conversion of woody biomass to chemicals, energy and materials. J. Biobased Mater. Bioenergy 2008, 2 , $100-120$.

2. Stipanovic, A.J.; Haghpanah, J.S.; Amidon, T.E.; Scott, G.M.; Barber, V.; Mishra, K. Opportunities for hardwood hemicellulose in biodegradable polymer blends. Mater. Chem. Energy For. Biomass 2007, 7, 107-120.

3. Zhang, Y.H.P.; Ding, S.Y.; Mielenz, J.R.; Cui, J.B.; Elander, R.T.; Laser, M.; Himmel, M.E.; McMillan, J.R.; Lynd, L.R. Fractionating recalcitrant lignocellulose at modest reaction conditions. Biotechnol. Bioeng. 2007, 97, 214-223.

4. Holladay, J.E.; Bozell, J.J.; White, J.F.; Johnson, D. Top Value-Added Chemicals from Biomass; DOE Report PNNL-16983; Pacific Northwest National Laboratory: Richland, WA, USA, 2007.

5. Goheen, D.W. Low Molecular Weight Chemicals. In Lignins: Occurrence, Formation, Structure, and Reactions; Sarkanen, K.V., Ludwig, C.H., Eds.; Wiley-Interscience: New York, NY, USA, 1971; pp. 797-804.

6. Ye, P.X.; Cheng, L.; Ma, H.; Bujanovic, B.; Goundalkar, M.; Amidon, T.E. Biorefinery with Water. In The Role of Green Chemistry in Biomass Processing and Conversion; Xie, H., Gathergood, N., Eds.; Wiley John \& Sons, Inc.: Hoboken, NJ, USA, 2013; pp. 135-180.

7. Amidon, T.E.; Bujanovic, B.; Liu, S.; Howard, J.R. Commercializing biorefinery technology: A case for the multi-product pathway to a viable biorefinery. Forests 2011, 2, 929-947.

8. Gong, C.; Goundalkar, M.; Bujanovic, B.; Amidon, T. Evaluation of different sulfur-free delignification methods for hot-water extracted hardwood. J. Wood Chem. Technol. 2012, 32, 93-104.

9. Karlsson, O.; Ikeda, T., Kishimoto, T.; Magar, K.; Mtsumoto, Y.; Hosoya, S. Isolation of lignin-carbohydrate bonds in wood. Model experiments and preliminary application to pine wood. J. Wood Sci. 2004, 50, 142-150.

10. Liu, S.; Fitzgerald, L.; Steeves, G.; Smith, A.; Mahmud, S.; Shupe, A.; Mukherjee, S.S. Biobutanol Production via Fermentation of Hot-Water Wood Extract Sugars. Presented at the Annual Conference of the American Institute of Chemical Engineers (AIChE), Philadelphia, PA, USA, 16-21 November 2008. 
11. Sun, Z.; Fitzgerald, L.; Mukherjee, S.S.; Liu, S. N-Butanol Production via Fermentation of Sugar Maple Wood Extract Hydrolysate. Presented at the Annual Conference of the American Institute of Chemical Engineers (AIChE), Nashville, TN, USA, 8-13 November 2009.

12. Hasan, A.; Bujanovic, B.; Amidon, T. Strength properties of kraft pulp produced from hot-water extracted wood chips within the biorefinery. J. Biobased Mater. Bioenergy 2010, 4, 46-52.

13. Al-Dajani, W.W.; Tschirner, U.; Jensen, T. Pre-extraction of hemicelluloses and subsequent kraft pulping Part II: Acid and autohydrolysis. TAPPI J. 2009, 8, 30-37.

14. Hergert, H.L. Developments in Organosolv Pulping-A Review. In Environmentally Friendly Technologies for the Pulp and Paper Industry; Young, R.A.; Akhtar, M. Eds.; John Wiley \& Sons, Inc.: New York, NY, USA, 1998; pp. 5-7.

15. Sjostrom, E. Wood Pulping. In Wood Chemistry. Fundamentals and Applications, 2nd ed.; Academic Press: San Diego, CA, USA, 1993; Chapter 7, pp. 148-149.

16. Johansson, A.; Aaltonen, O; Ylinen. P. Organosolv pulping-Methods and pulp properties. Biomass 1987, 13, 45-65.

17. Gong, C.; Goundalkar, M.J.; Bujanovic, B. Recovery of Lignin and Lignin Degradation Compounds after Acetone-Water-Oxygen Delignification (AWO). Presented at 243rd ACS Conference, San Diego, CA, USA, 25-29 March 2012.

18. Lora, J.H.; Glasser, W.G. Recent industrial applications of lignin: A sustainable alternative to nonrenewable materials. J. Polym. Environ. 2002, 10, 39-48.

19. Pye, E.K. Industrial Lignin Production and Applications. In Biorefineries-Industrial Processes and Products: Status Quo and Future Directions; Wiley-VCH Verlag GmbH: Weinheim, Germany, 2008; pp. 165-200.

20. Flynn, J.H.; Holder, C.D. A Guide to Useful Woods of the World, 2nd ed.; Forest Products Society: Madison, WI, USA, 2001; pp. 396-397.

21. Curley, A.D. Paulownia-growing rapidly outside Asia. J. For. 1993, 91, 41.

22. Caparrós, S.; Díaz, M.J.; Ariza, J.; López, F.; Jiménez, L. New perspectives for Paulownia fortunei L. valorisation of the autohydrolysis and pulping processes. Bioresour. Technol. 2008, 3, 741-749.

23. Barton, I.L.; Nicholas, I.D.; Ecroyd, C.E. Growth and Yield. In Paulownia; Forest Research Bulletin No. 231; Ensis: Rotorua, New Zealand, 2007; Chapter 10, p. 57.

24. Serapiglia, M.; Cameron, K.; Stipanovic, A.; Abrahamson, L.; Volk, T.; Smart, L. Yield and woody biomass traits of novel shrub willow hybrids at two contrasting sites. BioEnergy Res. 2013, 6, 533-546.

25. Zamudio, M.A.; Pérez, A.; López, F.; García, J.C.; Feria, M.J.; Alfaro, A. Neural fuzzy model applied to autohydrolysis of Paulownia trihybrid. J. Taiwan Inst. Chem. Eng. 2011, 42, 292-297.

26. Zhu, Z.H.; Chao, C.J.; Lu, X.Y.; Xiong, Y.G. Paulownia in China: Cultivation and Utilization; International Development Research Centre: Beijing, China, 1986; pp. 63-64.

27. Tang, R.C.; Carpenter, S.B.; Wittwer, R.F.; Graves, D.H. Paulownia-A crop tree for wood products and reclamation of surface-mined land. South. J. Appl. For. 1980, 4, 19-24.

28. Bergmann, B. Five years of Paulownia field trials in North Carolina. New For. 2003, 25, 185-199.

29. Tisserat, B.; Joshee, N.; Mahapatra, A.K.; Selling, G.W.; Finkenstadt, V.L. Physical and mechanical properties of extruded poly(lactic acid)-based Paulownia elongata biocomposites. Ind. Crop. Prod. 2013, 1, 88-96. 
30. Kang, K.H.; Jang, S.K.; Kim, B.; Park, M.K. Antibacterial phenylpropanoid glycosides from Paulownia tomentosa steud. Arch. Pharm. Res. 1994, 17, 470-475.

31. Gonçalves, V.M.F.; Evtuguin, D.V.; Domingues, M.R.M. Structural characterization of the acetylated heteroxylan from the natural hybrid Paulownia elongata/Paulownia fortunei. Carbohydr. Res. 2008, 343, 256-266.

32. Ates, S.; Ni, Y.; Akgul, M.; Tozluoglu, A. Characterization and evaluation of Paulownia elongota as a raw material for paper production. Afr. J. Biotechnol. 2008, 7, 4153-4158.

33. Fasching, M.; Schröder, P.; Wollboldt, R.P.; Weber, H.K.; Sixta, H. A new and facile method for isolation of lignin from wood based on complete wood dissolution. Holzforschung 2008, 62, 15-23.

34. Si, C.; Liu, Z.; Kim, J.; Bae, J. Structure elucidation of phenylethanoid glycosides from Paulownia tomentosa Steud. var. tomentosa wood. Holzforschung 2008, 62, 197-200.

35. Olson, J.; Carpenter, S. Specific gravity, fiber length, and extractive content of young Paulownia. Wood Fiber Sci. 1985, 17, 428-438.

36. Radeva, G.; Valchev, I.; Petrin, S.; Valcheva, E.; Tsekova, P. Kinetic study of the enzyme conversion of steam exploded Paulownia tomentosa to glucose. BioResources 2011, 7, 412-421.

37. Kalaycioglu, H.; Deniz, I.; Hiziroglu, S. Some of the properties of particleboard made from Paulownia. J. Wood Sci. 2005, 51, 410-414.

38. Akyildiz, M.; Kol, H. Some technological properties and uses of Paulownia (Paulownia tomentosa Steud.) wood. J. Environ. Biol. 2010, 31, 351-355.

39. Bose, S.K.; Francis, R.C.; Govender, M.; Bush, T.; Spark, A. Lignin content versus syringyl to guaiacyl ratio amongst poplars. Bioresour. Technol. 2009, 100, 1628-1633.

40. Goundalkar, M.J.; Corbett, D.B.; Bujanovic, B.M. Comparative analysis of milled wood lignins (MWL) isolated from sugar maple (SM) and hot-water extracted sugar maple (ESM). Energies 2014, in press.

41. Isenberg, I.H.; Harder, M.L.; Louden, L. Hardwoods. In Pulpwood of the United States and Canada, 3rd ed.; Georgia Institute of Technology, Institute of Paper Chemistry: Appleton, WI, Canada, 1981; Volume II, p. 97.

42. Dence, C.W. The Determination of Lignin. In Methods in Lignin Chemistry; Lin, S.Y., Dence, C.W., Eds.; Springer-Verlag Berlin Heidelberg: Berlin, Germany, 1992; pp. 33-61.

43. Guo, X.P.; Lai, Y.Z. Impact of Acid Pretreatments on the Reactivity of Wood Lignin. In Proceedings of the 14th International Symposium on Wood, Fiber and Pulping Chemistry (ISWFPC), Durban, South Africa, 25-28 June 2007.

44. Bolton, T.S.; Francis, R.C.; Amidon, T.E. Chemical and Physical Changes Due to Acidolysis of Chips Ahead of Alkaline Pulping. Presented at the 14th International Symposium on Wood, Fiber and Pulping Chemistry (ISWFPC), Durban, South Africa, 25-28 June 2007.

45. Leschinsky, M.; Zuckerstatter, G.; Weber, H.K.; Patt, R.; Sixta, H. Effect of autohydrolysis of Eucalyptus globules wood on lignin structure. Part 1: Comparison of different lignin fractions formed during water prehydrolysis. Holzforschung 2008, 62, 645-652.

46. Evtuguin, D.V.; Rocha, G.; Goodfellow, B.J. Detection of muconic acid type structures in oxidised lignins using 2D NMR spectroscopy, 10th EWLP, Stockholm, Sweden, August 25-28, 2008. Holzforschung 2009, 63, 675-680. 
47. Rencoret, J.; Marques, G.; Gutiérrez, A.; Nieto, L.; Jiménez-Barbero, J.; Martínez, Á.T.; del Río, J.C. Isolation and structural characterization of the milled-wood lignin from Paulownia fortune wood. Ind. Crop. Prod. 2009, 30, 137-143.

48. Kim, H.; Ralph, J. Solution-state 2D NMR of ball-milled plant cell wall gels in DMSO-d 6 /pyridine-d 5 . Org. Biomol. Chem. 2010, 8, 576-591.

49. Martínez Ferrer, Á.T.; Rencoret, J.; Nieto Garrido, L.; Jiménez-Barbero, J.; Gutiérrez Suárez, A.; Río Andrade, J.C.D. Selective lignin and polysaccharide removal in natural fungal decay of wood as evidenced by in situ structural analysis. Environ. Microbiol. 2011, 13, 96-107.

50. Wen, J.L.; Xue, B.L.; Xu, F.; Sun, R.C. Unveiling the structural heterogeneity of bamboo lignin by in situ HSQC NMR technique. BioEnergy Res. 2012, 5, 886-903.

51. Zarubin, M.Y.; Dejneko, I.P.; Evtuguin, D.V.; Robert, A. Delignification by oxygen in acetone-water media. Tappi J. 1989, 72, 163-168.

52. Bujanovic, B.; Hirth, K.C.; Ralph, S.A.; Reiner, R.S.; Atalla, R.H. Composition of the Organic Components in Polyoxometalate (POM) Liquors from Kraft Pulp Bleaching. Presented at the 14th International Symposium on Wood, Fibre and Pulp Chemistry (ISWFPC), Durban, South Africa, 25-28 June 2007.

(C) 2014 by the authors; licensee MDPI, Basel, Switzerland. This article is an open access article distributed under the terms and conditions of the Creative Commons Attribution license (http://creativecommons.org/licenses/by/3.0/). 